\title{
Total cardiovascular risk approach to improve efficiency of cardiovascular prevention in resource constrain settings
}

\author{
Shanthi Mendis, ${ }^{\mathrm{a}, *}$, Lars H. Lindholm ${ }^{\mathrm{b}}$, Simon G. Anderson ${ }^{\mathrm{c}}$, Ala Alwan ${ }^{\mathrm{a}}$, Rajendra Koju ${ }^{\mathrm{d}}$, \\ Basden J.C. Onwubere ${ }^{\mathrm{e}}$, Azhar Mahmood Kayani ${ }^{\mathrm{f}}$, Nihal Abeysinghe ${ }^{\mathrm{g}}$, Alfredo Duneas ${ }^{\mathrm{h}}$, \\ Sergo Tabagari ${ }^{\mathrm{i}}$, Wu Fan ${ }^{\mathrm{j}}$, Nizal Sarraf-Zadegan ${ }^{\mathrm{k}}$, Porfirio Nordet ${ }^{\mathrm{a}}$, Judith Whitworth ${ }^{1}$, \\ Anthony Heagerty ${ }^{\mathrm{c}}$ \\ ${ }^{a}$ Noncommunicable Diseases and Mental Health Cluster, World Health Organization, Geneva, Switzerland \\ ${ }^{\mathrm{b}}$ Public Health and Clinical Medicine, Umeå University, Sweden \\ ${ }^{\mathrm{c}}$ Division of Cardiovascular and Endocrine Sciences, University of Manchester, Manchester, UK \\ ${ }^{\mathrm{d}}$ Kathmandu University Teaching Hospital, Kathmandu, Nepal \\ ${ }^{\mathrm{e}}$ Department of Medicine, University of Nigeria Teaching Hospital, Nigeria \\ ${ }^{\mathrm{f}}$ Armed Forces and National Institute of Cardiology, Rawalpindi, Pakistan \\ ${ }^{\mathrm{g}}$ Epidemiology Unit, Ministry of Health, Colombo, Sri Lanka \\ ${ }^{\mathrm{h}}$ Preventive Cardiology Department, Cuban Institute of Cardiology, Havana, Cuba \\ ${ }^{\mathrm{i}}$ Aieti Medical School, Tbilisi, Georgia \\ ${ }^{\mathrm{j}}$ Chinese Centre for Disease Control and Prevention, Beijing, China \\ ${ }^{\mathrm{k}}$ Isfahan Cardiovascular Research Center, Isfahan University of Medical Sciences (IUMS), Isfahan, Iran \\ ${ }^{1}$ John Curtin School of Medical Research, Canberra, Australia \\ Accepted 2 February 2011; Published online 6 May 2011
}

\begin{abstract}
Objectives: To determine the population distribution of cardiovascular risk in eight low- and middle-income countries and compare the cost of drug treatment based on cardiovascular risk (cardiovascular risk thresholds $\geq 30 \% / \geq 40 \%$ ) with single risk factor cutoff levels.

Study Design and Setting: Using World Health Organization (WHO) and the International Society of Hypertension risk prediction charts, cardiovascular risk was categorized in a cross-sectional study of 8,625 randomly selected people aged 40-80 years (mean age, 54.6 years) from defined geographic regions of Nigeria, Iran, China, Pakistan, Georgia, Nepal, Cuba, and Sri Lanka. Cost estimates for drug therapy were calculated for three countries.

Results: A large fraction (90.0-98.9\%) of the study population has a 10-year cardiovascular risk $<20 \%$. Only $0.2-4.8 \%$ are in the high-risk categories $(\geq 30 \%)$. Adopting a total risk approach and WHO guidelines recommendations would restrict unnecessary drug treatment and reduce the drug costs significantly.

Conclusion: Adopting a total cardiovascular risk approach instead of a single risk factor approach reduces health care expenditure by reducing drug costs. Therefore, limited resources can be more efficiently used to target high-risk people who will benefit the most. This strategy needs to be complemented with population-wide measures to shift the cardiovascular risk distribution of the whole population. (C) 2011 Elsevier Inc. All rights reserved.
\end{abstract}

Keywords: Preventive cardiology; Hypertension; Health policy; Risk; Cost saving; Atherosclerosis

\section{Introduction}

Cardiovascular disease (CVD) is a leading cause of mortality and contributes to one-third of all global deaths [1,2].

* Corresponding author. Chronic Disease Prevention and Management, World Health Organization, 20 Ave. Appia, CH-1211, Geneva 27, Geneva, Switzerland. Tel.: +41-22-791-3441; fax: 41-22-791-4151.

E-mail address: mendis@who.int (S. Mendis).
About three-quarters of the global mortality and disease burden from CVD is borne by low- and middle-income countries (LMICs) [3-7]. Projections for global mortality and burden of disease from World Health Organization (WHO) estimates for 2002 indicate that CVD is likely to remain in the top three leading causes in 2030 , regardless of the predictive scenarios used to derive these estimates [8].

The estimated 17 million CVD deaths every year are mainly because of heart attacks, strokes, and cardiac failure, 


\section{What is new?}

What was already known about this topic?

- Effective CVD prevention requires a paradigm shift from the treatment of single risk factors in isolation, to the management of total cardiovascular risk. This is supported by evidence that the cost-effectiveness of managing hypertension and hypercholesterolemia is influenced by the overall risk of CVD among patients, not simply by the level of the risk factor.

- Over the last decade, total risk assessment and management have been recommended by cardiovascular $(\mathrm{CV})$ prevention guidelines in most high-income countries based on CV risk prediction equations/scores or charts derived from various sources in developed countries.

- Cost implications of changing the single risk factor approach to total risk factor approach has not been previously investigated in LMIC.

What we know after this paper.

- WHO and the International Society of hypertension (ISH) have generated 14 WHO/ISH Risk prediction charts to be used in countries of each specific WHO epidemiological sub-regions; these were generated using the best available data of countries of each specific WHO epidemiological sub-region.

- We used corresponding WHO/ISH Risk prediction charts in a representative population sample from 8 LMIC to 1) generate information on the distribution cardiovascular risk 2) estimate the cost of preventing heart attacks and strokes using the total cardiovascular risk approach and compare it with the cost of using the single risk factor approach.

- Our data show that the total risk approach would restrict unnecessary drug treatment and reduce the drug costs almost by 50\%. This approach therefore provides a way to use limited resources more efficiently by targeting high risk people who will benefit the most.

which are caused by one or more cardiovascular risk factors including tobacco use, hypertension, hypercholesterolemia, and diabetes [3-5,7]. Heart attacks and stroke are preventable if cost-effective interventions that reduce cardiovascular risk can be made accessible to people [6,9]. Cardiovascular risk can be reduced through conventional management of single risk factors (hypertension, hypercholesterolemia, etc.) or by applying a total cardiovascular risk approach. Often conventional single risk factor approach leaves patients at an unacceptably high risk of cardiovascular events because of suboptimal control and failure to address other coexistent risk factors. Effective CVD prevention requires a paradigm shift from the treatment of single risk factors in isolation to the management of total cardiovascular risk [6,9]. This is supported by evidence that the cost-effectiveness of managing hypertension and hypercholesterolemia is influenced by the overall risk of CVD among patients, not simply by the level of the risk factor [10].

The new WHO guidelines for primary prevention of CVD recommend total cardiovascular risk assessment before making decisions on drug treatment including lipid-lowering therapy [6]. According to the guidelines, the threshold for pharmacologic intervention in the public health sector needs to be decided by the Ministries of Health, based on available resources. It is recommended that pharmacologic treatment should be provided for all people at least when their calculated 10 -year CVD risk is $30 \%$ or more. However, the risk threshold for drug treatment should be lowered to $20 \%$ if and when resources permit. For the development and implementation of programs for the prevention of heart attacks and strokes, it is necessary to have information on the percentage of the population in low, medium, or high cardiovascular risk categories. At present, these data are not available for LMIC, and the cost implications of shifting the cutoff for drug treatment have not been previously investigated. If available, such information would enable those involved in designing health care policy to decide on cutoff level for drug treatment based on available resources.

The World Health Organization and the International Society of Hypertension (WHO/ISH) risk prediction charts have been developed to specifically enhance implementation of an integrated and cost-effective approach by physician and nonphysician health workers to prevent heart attacks and stroke in low-resource settings. Several equations have been developed previously to predict individual absolute risk of a cardiovascular event over a specified time period [11-13]. Most of these equations have been derived from Caucasian populations in developed countries and are not necessarily valid in other populations. These charts are based on population-based observational data of risk factors and outcomes (heart attacks and stroke) analyzed longitudinally and have the same goal as existing risk equations such as those based on Framingham and SCORE [11,12]. The WHO/ISH risk prediction charts were based on standardized collection and assessment of data on risk factor prevalence and relative risk by WHO epidemiologic subregion from the Comparative Risk Assessment Project [14], conducted by the WHO. Absolute risk of cardiovascular event was determined by scaling individual relative risk to population incidence rates of major CVDs, estimated from the global burden of disease study $[6,15,16]$. The charts were designed to enable cardiovascular risk assessment and prediction in LMIC populations of all WHO subregions [6]. 
Data from the Asia Pacific Cohort Studies Collaboration [17-21] were used in the preparation of these charts.

In this study, the WHO/ISH risk predictor charts are applied to cross-sectional population samples from eight LMICs (Nigeria, Iran, China, Pakistan, Georgia, Nepal, Cuba, and Sri Lanka) that do not have locally developed algorithms to predict CVD risk. The major underlying assumption that relative cardiovascular risks and the correlations between risk factors are constant across different populations is supported by the recent case-controlled INTERHEART study [22]. The burden of coronary heart disease in the participating countries ranges from less than nine disability-adjusted life years (DALYs) lost per year in China and Sri Lanka to 20-29 in Georgia; the global burden of stroke ranges from less than nine DALYs per year in Cuba to $15-19$ in Georgia. The number of deaths from coronary heart disease and stroke and the prevalence of major risk factors also vary among the participating countries [23]. These data will provide the baseline for further research to validate these charts for individual countries and confirm in these scenarios the effect and benefit of WHO recommendation on this subject $[6,9,16]$.

The objectives of the present study were as follows

1. To determine the percentage of the population in each cardiovascular risk category based on the WHO/ISH risk prediction charts in a sample from eight LMICs selected from eight WHO epidemiologic subregions.

2. To compare the cost of giving drug treatment using cardiovascular risk thresholds $(\geq 30 \%)$ with single risk factor cutoff levels (blood pressure $[\mathrm{BP}] \geq 140$ / $90 \mathrm{~mm} \mathrm{Hg}$ and total cholesterol [TC] $\geq 6.0 \mathrm{mmol} /$ L). Three participating countries with reliable data on prices of medicine have been used to address the second objective [24].

\section{Methods}

A cross-sectional study was conducted in defined areas in eight selected countries (Nigeria, Iran, China, Pakistan, Georgia, Nepal, Cuba, and Sri Lanka), selected from eight WHO epidemiologic subregions. The selection was based on the willingness of a team of investigators in each of these countries to conduct the study according to an agreed protocol. The estimates of the sample size were based on prevalence data on hypertension in the adult population of each selected area. A sample of individuals $(n=8,625)$ aged 40-80 years were drawn from the general population using a household survey. Samples were taken from geographically defined areas that have urban or rural and socioeconomic representation comparable with that of the general population, preferably within five miles $(8.046 \mathrm{~km})$ from the implementing institution. Cluster random sampling of households was used to select a sample of 1,000 households. The first 10 clusters were randomly selected from the geographically defined area using lists of municipal wards, Grama sevaka divisions, or other administrative units. Each cluster was large enough for the random selection of 100 households based on electoral, census, or other lists of households.

Randomly selected households in each cluster were visited by a fieldworker who recorded the number of adults aged 40-80 years in each household and provided them with information about the purpose of the study. All residents of each of the selected household within the age group 40-80 years were invited to participate in the study by attending a health clinic. Participants were fasted (no food, nor drink, other than water in the 12 preceding hours). Basic information, including name, age, mailing, and contact information, of each eligible subject was entered into a household verification form. Those who were not 40-80 years old; those with confirmed coronary heart disease, cerebrovascular disease, or peripheral arterial disease; and those who did not give consent were excluded from the study. Among those excluded, there were more men than women and more young than elderly.

Invited participants were screened in 10 health clinics and seen by a physician who checked for a history of symptoms suggestive of stable angina, unstable angina, myocardial infarction, transient ischemic attacks, strokes, and peripheral vascular disease. Data on cigarette smoking and family history of premature CVD were collected using a standard data entry form. BP was measured using a standard mercury sphygmomanometer on the left arm after five minutes rest with the subject in the sitting position. The first and fifth phase of Korotkoff sounds were used for systolic blood pressure (SBP) and diastolic blood pressure (DBP), respectively. Two independent measurements were obtained with an interval of at least 10 minutes; the second measurement was taken for data analysis. In selected cases, an electrocardiogram was recorded based on the discretion of the physician to confirm coronary heart disease.

Fasting blood samples were taken from a finger puncture. Dry chemistry tests were used to measure TC and fasting blood glucose level using the Accutrend GC System (Accutrend GC; Roche Diagnostics, Germany). Measuring ranges of the device for glucose are $1.1-33.3 \mathrm{mmol} / \mathrm{L}$ and for cholesterol $3.88-7.76 \mathrm{mmol} / \mathrm{L}$. Precision for glucose is $<3 \%$ and for cholesterol $<5 \%$.

The WHO/ISH risk prediction charts were used to grade cardiovascular risk $[6,16]$. These charts use age (1: 40-49; 2: 50-59; 3: 60-69;4: 70 years and older), sex (0: male; 1 : female), smoking (0: no; 1: smoker or ex-smoker $<12$ months), SBP (1: <140 mm Hg; 2: 140 to $<160 ; 3: 160$ to $<180 ; 4$ : $\geq 180$ ), blood cholesterol (4: TC, $<5 \mathrm{mmol} /$ L; 5: TC, 5 to $<6$; 6 : TC, 6 to $<7$; 7: TC, 7 to $<8$; 8 : TC, 8 and more), and presence or absence of diabetes (0: Yes, fasting blood glucose $\geq 7 \mathrm{mmol} / \mathrm{L}, 126 \mathrm{mg} \%$; 1 : No, fasting blood glucose $<7$ to grade cardiovascular risk) (Fig. 1). There are two sets, one for settings where blood cholesterol can be measured and the other for settings in which blood cholesterol cannot be measured [6]. In this study, we have used the charts for settings where blood cholesterol can be measured. The charts provide 

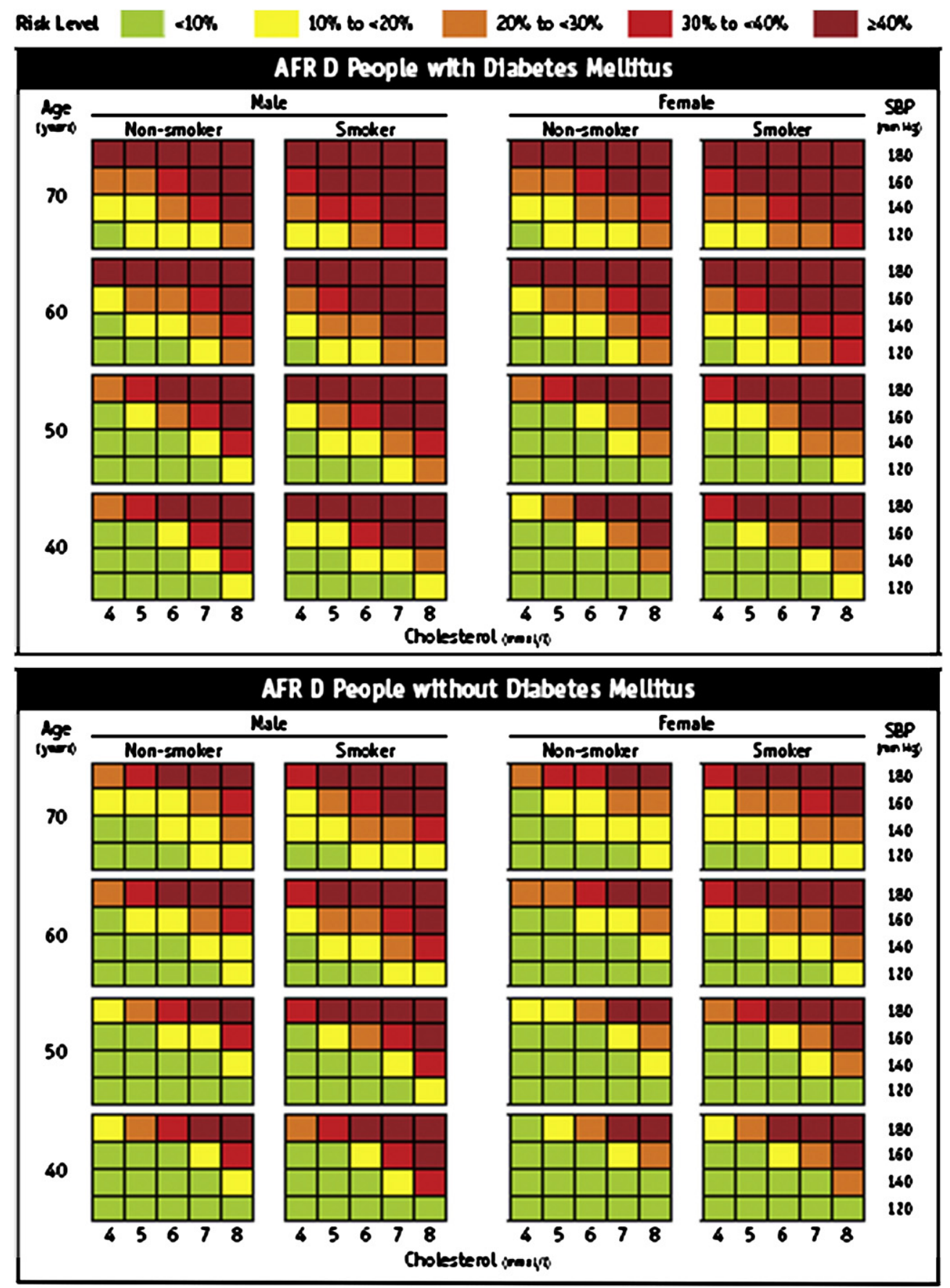

Fig. 1. An example of the World Health Organization and the International Society of Hypertension (WHO/ISH) risk prediction chart for use in settings where blood cholesterol can be measured. (This chart can only be used for countries of the WHO region for Africa subregion D, in settings where blood cholesterol can be measured. There are two sets of charts. One can be used in settings where blood cholesterol can be measured, whereas the other in settings where blood cholesterol cannot be measured. Both sets are available according to the 14 WHO epidemiologic subregions [6].) WHO/ISH risk prediction chart WHO Region for Africa (subregion D) 10-year risk of a fatal or nonfatal cardiovascular event by gender, age, SBP, total blood cholesterol, smoking status, and presence or absence of diabetes mellitus. SBP, systolic blood pressure.

evidence-based recommendations on specific preventive actions to initiate and with what degree of intensity. The risk categories for 10-year combined acute myocardial infarction and stroke (fatal and nonfatal) are as follows: less than $10 \%, 10$ to $<20 \%, 20$ to $<30 \%, 30$ to $<40 \%$, and $\geq 40 \%$ [6].

\subsection{Statistical analysis}

Epi Info version 3.3.2 for Windows and Excel file 2003 software (Microsoft Corp., Redmond, WA) were used for data entry, transfer, and processing. We used the perprotocol method for analysis of data. Cost estimates were 
calculated for Pakistan, Nepal, and Sri Lanka, as an example. For estimating the cost of medicines per million per year (population aged 40 years or older), we used the lowest price generic preparation of each drug class available in the market (aspirin, thiazide diuretics, statins, and angiotensinconverting enzyme inhibitors). For calculation of costs based on the single risk factor approach, we included all people with BP $\geq 140 / 90$ and/or TC $\geq 6$ mmol. For calculation of costs based on the cardiovascular risk approach, we included the following categories: (1) people with high cardiovascular risk ( $\geq 30 \%$ ), who are recommended four drugs [6]; and (2) people with cardiovascular risk $\geq 30 \%$ and people with cardiovascular risk $<30 \%$ but with $\mathrm{BP} \geq 160 / 100$, who are recommended antihypertensive treatment, and people with cardiovascular risk $<30 \%$ but with $\mathrm{TC} \geq 8 \mathrm{mmol} / \mathrm{L}$, who are recommended statin therapy.

\section{Results}

A total of $8,625(3,295,38.2 \%$ men) participants who satisfied the inclusion criteria from eight populations participated in the study. The mean age was about 54.6 years (men, 55.6 years; women, 54.3 years) (Table 1). The participation rate was about $80.6 \%$ (range, $73.3 \%$ [Iran] to $90.0 \%$ [China]).

The prevalence of risk factors in the sample was as follows: fasting blood glucose $>7 \mathrm{mmol} / \mathrm{L}=7.6 \%$, smoking $=22.1 \%$, total blood cholesterol $\geq 6 \mathrm{mmol} / \mathrm{L}=12.1 \%$, $\mathrm{SBP} \geq 140 \mathrm{~mm} \mathrm{Hg}=33.3 \%, \mathrm{DBP} \geq 90 \mathrm{~mm} \mathrm{Hg}=26.9 \%$, body mass index (BMI) 25-29.9=30.9, and BMI $\geq 30=21.3 \%$. The prevalence of risk factors was highest in Georgia and Iran Table 2.

The distribution of cardiovascular risk in the population is shown in Table 3. Most people in all populations had a low $(<10 \%)$ 10-year cardiovascular risk (range, 79.2\% [Pakistan] to $96.1 \%$ [China]), and a large fraction $(90.0-98.9 \%)$ of the study population had cardiovascular risk $<20 \%$. The percentage of the population with a cardiovascular risk $\geq 20$ was less than $10 \%$ in all populations (Pakistan, 10.0\%; Georgia, 9.6\%; Nigeria, 5.0\%; Cuba, 2.8\%; Sri Lanka, 2.2\%; Iran, 1.7\%; and China, $1.1 \%$ ) Table 3.

Table 1. Total cardiovascular risk thresholds for prevention of heart attacks and strokes in limited resource settings; implications for health policy (country, age and sex distribution, and mean age)

\begin{tabular}{|c|c|c|c|c|c|c|c|}
\hline \multirow[b]{2}{*}{ Country and WHO-subregion } & \multirow[b]{2}{*}{ Gender } & \multirow[b]{2}{*}{ Total $n(\%)$} & \multicolumn{5}{|c|}{ Age (years) } \\
\hline & & & $40-49$ & $50-59$ & $60-69$ & $\geq 70$ & Mean (SD) \\
\hline Nigeria/AFR D & $\begin{array}{l}\text { Female } \\
\text { Male } \\
\text { Total }\end{array}$ & $\begin{array}{c}766(70.5) \\
321(29.5) \\
1,087\end{array}$ & $\begin{array}{r}213 \\
54 \\
267\end{array}$ & $\begin{array}{r}210 \\
74 \\
284\end{array}$ & $\begin{array}{r}197 \\
93 \\
290\end{array}$ & $\begin{array}{l}146 \\
100 \\
246\end{array}$ & $\begin{array}{l}56.8(110.1) \\
60.4(19.7) \\
57.8(110.1)\end{array}$ \\
\hline Cuba/AMR A & $\begin{array}{l}\text { Female } \\
\text { Male } \\
\text { Total }\end{array}$ & $\begin{array}{c}835(64.9) \\
452(35.1) \\
1,287\end{array}$ & $\begin{array}{l}302 \\
162 \\
464\end{array}$ & $\begin{array}{l}233 \\
107 \\
340\end{array}$ & $\begin{array}{l}229 \\
146 \\
375\end{array}$ & $\begin{array}{r}71 \\
37 \\
108\end{array}$ & $\begin{array}{l}54.6(19.9) \\
55.4(19.9) \\
54.9(19.9)\end{array}$ \\
\hline Iran/EMR B & $\begin{array}{l}\text { Female } \\
\text { Male } \\
\text { Total }\end{array}$ & $\begin{array}{c}595(57.9) \\
432(42.1) \\
1,027\end{array}$ & $\begin{array}{l}283 \\
159 \\
442\end{array}$ & $\begin{array}{l}217 \\
140 \\
357\end{array}$ & $\begin{array}{r}86 \\
116 \\
202\end{array}$ & $\begin{array}{r}9 \\
17 \\
26\end{array}$ & $\begin{array}{l}50.6(17.5) \\
53.9(18.7) \\
52.0(18.2)\end{array}$ \\
\hline Pakistan/EMR D & $\begin{array}{l}\text { Female } \\
\text { Male } \\
\text { Total }\end{array}$ & $\begin{array}{c}620(54.8) \\
512(45.2) \\
1,132\end{array}$ & $\begin{array}{l}262 \\
131 \\
393\end{array}$ & $\begin{array}{l}164 \\
159 \\
323\end{array}$ & $\begin{array}{l}145 \\
160 \\
305\end{array}$ & $\begin{array}{r}49 \\
62 \\
111\end{array}$ & $\begin{array}{l}52.7(19.7) \\
56.4(19.3) \\
54.4(19.7)\end{array}$ \\
\hline Georgia/EUR B & $\begin{array}{l}\text { Female } \\
\text { Male } \\
\text { Total }\end{array}$ & $\begin{array}{c}750(66.2) \\
383(33.8) \\
1,133\end{array}$ & $\begin{array}{l}257 \\
110 \\
367\end{array}$ & $\begin{array}{l}267 \\
130 \\
397\end{array}$ & $\begin{array}{l}202 \\
119 \\
321\end{array}$ & $\begin{array}{l}24 \\
24 \\
48\end{array}$ & $\begin{array}{l}54.2(18.9) \\
56.1(18.8) \\
54.8(18.9)\end{array}$ \\
\hline Sri Lanka/SEAR B & $\begin{array}{l}\text { Female } \\
\text { Male } \\
\text { Total }\end{array}$ & $\begin{array}{c}800(72.8) \\
299(27.2) \\
1,099\end{array}$ & $\begin{array}{r}273 \\
98 \\
371\end{array}$ & $\begin{array}{r}305 \\
98 \\
403\end{array}$ & $\begin{array}{r}203 \\
88 \\
291\end{array}$ & $\begin{array}{l}19 \\
15 \\
34\end{array}$ & $\begin{array}{l}54.9(18.8) \\
53.6(18.4) \\
54.0(18.5)\end{array}$ \\
\hline Nepal/SEAR D & $\begin{array}{l}\text { Female } \\
\text { Male } \\
\text { Total }\end{array}$ & $\begin{array}{c}316(52.7) \\
284(47.3) \\
600\end{array}$ & $\begin{array}{l}129 \\
100 \\
229\end{array}$ & $\begin{array}{r}97 \\
90 \\
187\end{array}$ & $\begin{array}{r}78 \\
73 \\
151\end{array}$ & $\begin{array}{l}12 \\
21 \\
33\end{array}$ & $\begin{array}{l}52.8(18.8) \\
54.3(19.1) \\
53.5(19.0)\end{array}$ \\
\hline China/WPR B & $\begin{array}{l}\text { Female } \\
\text { Male } \\
\text { Total }\end{array}$ & $\begin{array}{c}648(51.4) \\
612(48.6) \\
1,260\end{array}$ & $\begin{array}{l}195 \\
182 \\
377\end{array}$ & $\begin{array}{l}248 \\
259 \\
507\end{array}$ & $\begin{array}{l}176 \\
147 \\
323\end{array}$ & $\begin{array}{l}29 \\
24 \\
53\end{array}$ & $\begin{array}{l}54.3(17.9) \\
54.9(18.3) \\
54.6(18.1)\end{array}$ \\
\hline Total $N(\%)$ & $\begin{array}{l}\text { Female } \\
\text { Male } \\
\text { Total }\end{array}$ & $\begin{array}{l}5,330(61.8) \\
3,295(38.2) \\
8,625(100.0)\end{array}$ & $\begin{array}{r}1,914(65.8) \\
996(34.2) \\
2,910(33.7)\end{array}$ & $\begin{array}{l}1,740(62.2) \\
1,058(37.8) \\
2,799(32.5)\end{array}$ & $\begin{array}{r}1,316(58.3) \\
942(41.7) \\
2,258(26.2)\end{array}$ & $\begin{array}{l}359(54.5) \\
300(45.5) \\
659(7.6)\end{array}$ & $\begin{array}{l}54.3(19.2) \\
55.6(19.1) \\
54.6(19.2)\end{array}$ \\
\hline
\end{tabular}

Abbreviations: WHO, World Health Organization; SD, standard deviation; AFR D, WHO region for Africa subregion D; AMR A, WHO region for the Americas subregion A; EMR B, WHO region for Eastern Mediterranean subregion B; EUR B, WHO region for Europe subregion B; SEAR B, WHO region for South-East Asia subregion B; SEAR D, WHO region for South-East Asia subregion D; WPR B, WHO region for Western Pacific subregion B. 


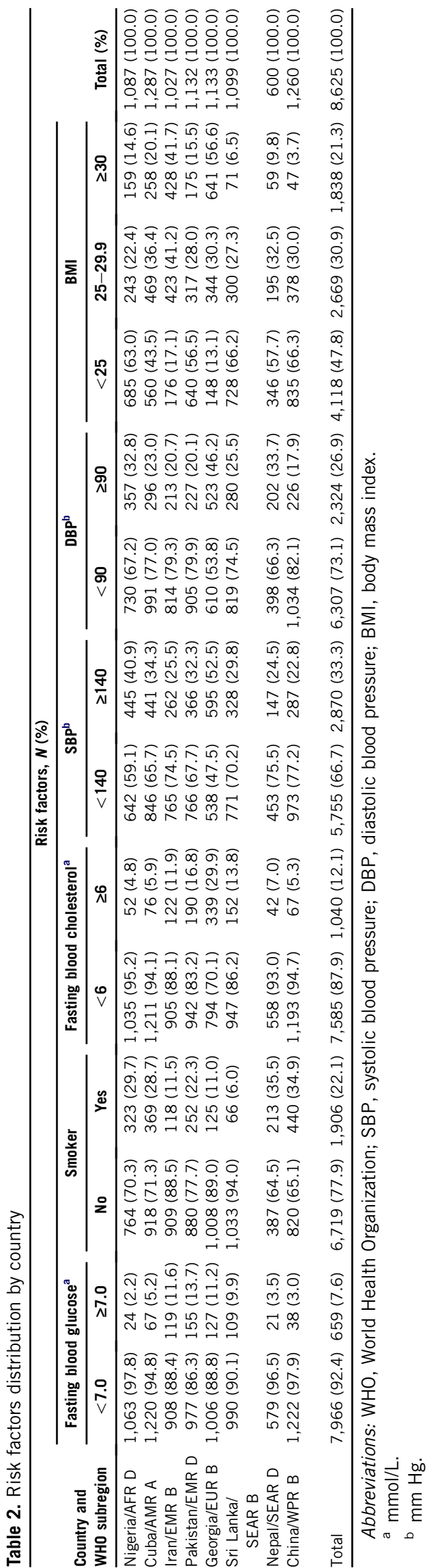

If $\mathrm{a} \geq 30 \%$ threshold is used for drug treatment, $1.9 \%$ of the population requires drug treatment (range, $0.4 \%$ in China to $4.8 \%$ in Pakistan). Lowering the cardiovascular risk threshold (from $30 \%$ to $20 \%$ ) would increase about twofold the number of people requiring treatment (1.9\% [167 of $8,625]$ to $4.5 \%$ [ 389 of 8,625$]$ ). The consequence is a substantial increase in health care expenditure Table 4. On the other hand, if a single risk factor approach is used and all those with hypertension (a persistent SBP $\geq 140$ and/or DBP $\geq 90)$ and high fasting blood cholesterol $(\geq 6 \mathrm{mmol} / \mathrm{L})$ are treated, about $50.0 \%(4,414$ of 8,625$)$ of the sample would require drug treatment $(39.1 \%$ antihypertensives and 12.1 lipid-lowering drugs); more than 10-fold higher than with the total cardiovascular risk approach $(\geq 30 \%=$ $1.9 \%, \geq 20 \%=4.5 \%$ ) Table 4 .

The risk-benefit ratio for drug treatment is higher when the cutoff used is $\geq 140 / 90$ and lower when the cutoff used is SBP $\geq 160$ and/or DBP $\geq 100 \mathrm{~mm} \mathrm{Hg}$ [6,25-29]. Younger adults with a $B P \geq 160 / 100$ are likely to fall into a risk category below $30 \%$ if they do not have other risk factors. Furthermore, there is also a low risk-benefit ratio with statin treatment if the cutoff used is TC $\geq 8 \mathrm{mmol} / \mathrm{L}[6,30,31]$. Therefore, WHO guideline recommends drug treatment for those with a persistent elevated BP $\geq 160 / 100 \mathrm{~mm} \mathrm{Hg}$ and/ or $\mathrm{TC} \geq 8 \mathrm{mmol} / \mathrm{L}[6]$.

Including individuals with raised BP $(\geq 160 / 100 \mathrm{~mm}$ $\mathrm{Hg}$ ) but with a 10 -year CVD risk $<30 \%$ or $<20 \%$ would increase the percentage of people requiring drug treatment to $15.5 \%$ and $16.0 \%$, respectively. This figure is still threefold less than with the single risk factor approach Table 4.

We compared the estimated annual cost of medicines per million population for implementing the total risk approach vs. the single risk factor approach in selected countries. The estimate shows that if the single risk factor approach is applied in Pakistan with its percentage of population at risk and the lower price of medicine in this country, the cost per million population (aged 40 years or older) of treating those with $\mathrm{BP} \geq 140 / 90$ and blood cholesterol $\geq 6 \mathrm{mmol} / \mathrm{L}$ would be $27,128,625$ US\$; if the absolute risk approach is used in Pakistan, the cost of treating those with 10-year risk of CVD $\geq 30 \%$ per million population (aged 40 years or older) would be $5,431,200$, about fivefold less. If we include those with BP $\geq 160 / 100 \mathrm{~mm} \mathrm{Hg}$ and blood cholesterol $\geq 8 \mathrm{mmol} / \mathrm{L}$, but with 10 -year CVD risk of less than $30 \%$ the cost would be 11,020,262, 2.3-fold less (Table 5). The estimated annual cost of medicines per million population in Nepal using the single risk factor approach would be $17,562,011$ US $\$$. The cost decreases by about sevenfold $(\mathbf{2 , 3 7 5 , 3 4 7}$ US\$) if using the 10-year risk of CVD $\geq 30 \%$ and to about threefold less $(\mathbf{5 , 8 1 7 , 6 2 5 )}$ if those with $\mathrm{BP} \geq 160 / 100$ and blood cholesterol $\geq 8 \mathrm{mmol} / \mathrm{L}$ are included (Table 6). The estimated annual cost of medicines per million population in Sri Lanka using the single risk factor approach would be $\mathbf{3 , 4 7 2 , 6 1 0}$ US\$. The cost decreases by about 11 -fold if a 10 -year cardiovascular risk threshold $30 \%$ is used and to about 4.6-fold less if those 
Table 3. Distribution of predicted 10-year cardiovascular risk (fatal or nonfatal) by gender in eight populations

\begin{tabular}{|c|c|c|c|c|c|c|}
\hline \multirow[b]{2}{*}{ Country and WHO subregion } & \multirow[b]{2}{*}{ Sex } & \multicolumn{5}{|c|}{10 -year cardiovascular risk $(\%[n / N])$} \\
\hline & & $<10 \%$ & $10 \%$ to $<20 \%$ & $20 \%$ to $<30 \%$ & $30 \%$ to $<40 \%$ & $\geq 40 \%$ \\
\hline Nigeria/AFR D & $\begin{array}{l}\text { Male } \\
\text { Female } \\
\text { Total }\end{array}$ & $\begin{array}{l}80.4(258 / 321) \\
88.4(677 / 766) \\
86.0(935 / 1,087)\end{array}$ & $\begin{array}{l}14.3(46 / 321) \\
6.8(52 / 766) \\
9.0(98 / 1,087)\end{array}$ & $\begin{array}{l}2.5(8 / 321) \\
2.7(21 / 766) \\
2.7(29 / 1,087)\end{array}$ & $\begin{array}{l}1.9(6 / 321) \\
1.8(14 / 766) \\
1.8(20 / 1,087)\end{array}$ & $\begin{array}{l}0.9(3 / 321) \\
0.3(2 / 766) \\
0.5(5 / 1,087)\end{array}$ \\
\hline Cuba/AMR A & $\begin{array}{l}\text { Male } \\
\text { Female } \\
\text { Total }\end{array}$ & $\begin{array}{l}83.4(377 / 452) \\
93.1(778 / 835) \\
89.7(1,155 / 1,287)\end{array}$ & $\begin{array}{l}11.9(54 / 452) \\
4.9(41 / 835) \\
7.4(95 / 1,287)\end{array}$ & $\begin{array}{l}3.3(15 / 452) \\
1.0(8 / 835) \\
1.8(23 / 1,287)\end{array}$ & $\begin{array}{l}0.9(4 / 452) \\
0.4(3 / 835) \\
0.5(7 / 1,287)\end{array}$ & $\begin{array}{l}0.4(2 / 452) \\
0.6(5 / 835) \\
0.5(7 / 1,287)\end{array}$ \\
\hline Iran/EMR B & $\begin{array}{l}\text { Male } \\
\text { Female } \\
\text { Total }\end{array}$ & $\begin{array}{l}93.5(404 / 432) \\
94.1(560 / 595) \\
93.9(964 / 1,027)\end{array}$ & $\begin{array}{l}5.3(23 / 432) \\
3.9(23 / 595) \\
4.5(46 / 1,027)\end{array}$ & $\begin{array}{l}0.5(2 / 432) \\
1.7(19 / 595) \\
1.2(12 / 1,027)\end{array}$ & $\begin{array}{l}0.5(2 / 432) \\
0.2(1 / 595) \\
0.3(3 / 1,027)\end{array}$ & $\begin{array}{l}0.2(1 / 432) \\
0.2(1 / 595) \\
0.2(2 / 1,027)\end{array}$ \\
\hline Pakistan/EMR D & $\begin{array}{l}\text { Male } \\
\text { Female } \\
\text { Total }\end{array}$ & $\begin{array}{l}71.5(366 / 512) \\
85.6(531 / 620) \\
79.2(897 / 1,132)\end{array}$ & $\begin{aligned} & 13.7(70 / 512) \\
& 8.4(52 / 620) \\
& 10.8(122 / 1,132)\end{aligned}$ & $\begin{array}{l}7.4(38 / 512) \\
3.4(21 / 620) \\
5.2(59 / 1,132)\end{array}$ & $\begin{array}{l}2.7(14 / 512) \\
1.1(7 / 620) \\
1.9(21 / 1,132)\end{array}$ & $\begin{array}{l}4.7(24 / 452) \\
1.5(9 / 620) \\
2.9(33 / 1,132)\end{array}$ \\
\hline Georgia/EUR B & $\begin{array}{l}\text { Male } \\
\text { Female } \\
\text { Total }\end{array}$ & $\begin{array}{l}78.6(301 / 383) \\
85.5(641 / 750) \\
83.1(942 / 1,133)\end{array}$ & $\begin{array}{l}9.9(38 / 383) \\
5.9(44 / 750) \\
7.2(82 / 1,133)\end{array}$ & $\begin{array}{l}7.0(27 / 383) \\
6.1(46 / 750) \\
6.4(73 / 1,133)\end{array}$ & $\begin{array}{l}1.8(7 / 383) \\
0.3(2 / 750) \\
0.8(9 / 1,133)\end{array}$ & $\begin{array}{l}2.6(10 / 383) \\
2.3(17 / 750) \\
2.4(27 / 1,133)\end{array}$ \\
\hline Sri Lanka/SEAR B & $\begin{array}{l}\text { Male } \\
\text { Female } \\
\text { Total }\end{array}$ & $\begin{array}{l}95.3(285 / 299) \\
94.8(758 / 800) \\
94.9(1,043 / 1,099)\end{array}$ & $\begin{array}{l}3.0(9 / 299) \\
2.8(22 / 800) \\
2.8(31 / 1,099)\end{array}$ & $\begin{array}{l}1.0(3 / 299) \\
0.8(6 / 800) \\
0.8(9 / 1,099)\end{array}$ & $\begin{array}{l}-(0 / 299) \\
1.0(8 / 800) \\
0.7(8 / 1,099)\end{array}$ & $\begin{array}{l}0.7(2 / 299) \\
0.8(6 / 800) \\
0.7(8 / 1,099)\end{array}$ \\
\hline Nepal/SEAR D & $\begin{array}{l}\text { Male } \\
\text { Female } \\
\text { Total }\end{array}$ & $\begin{array}{l}87.0(247 / 284) \\
87.3(276 / 316) \\
87.2(523 / 600)\end{array}$ & $\begin{array}{l}9.2(26 / 284) \\
9.8(31 / 316) \\
9.5(57 / 600)\end{array}$ & $\begin{array}{l}1.8(5 / 286) \\
0.9(3 / 316) \\
1.3(8 / 600)\end{array}$ & $\begin{array}{l}1.8(5 / 286) \\
0.9(3 / 316) \\
1.3(8 / 600)\end{array}$ & $\begin{array}{l}0.4(1 / 284) \\
0.9(3 / 316) \\
1.3(4 / 600)\end{array}$ \\
\hline China/WPR B & $\begin{array}{l}\text { Male } \\
\text { Female } \\
\text { Total }\end{array}$ & $\begin{array}{l}93.6(573 / 612) \\
98.5(638 / 648) \\
96.1(1,211 / 1,260)\end{array}$ & $\begin{array}{l}5.2(32 / 612) \\
0.5(3 / 648) \\
2.8(35 / 1,260)\end{array}$ & $\begin{array}{l}0.5(3 / 612) \\
0.9(6 / 648) \\
0.7(9 / 1,260)\end{array}$ & $\begin{array}{c}0.2(1 / 612) \\
-(0 / 648) \\
0.1(1 / 1,260)\end{array}$ & $\begin{array}{l}0.5(3 / 612) \\
0.2(1 / 648) \\
0.3(4 / 1,260)\end{array}$ \\
\hline
\end{tabular}

Abbreviation: WHO, World Health Organization.

with BP 160/100 and blood cholesterol $8 \mathrm{mmol} / \mathrm{L}$ are also included in the treatment (Table 7). The cost estimation is different in the three countries because of the differences in the percentage of population at different levels of risk and the differences in the price of generic medicines. The focus of the study was on drug costs because it is the most important contributor to overall direct costs. We assume that other costs of service delivery, such as health facilities, follow-up, and wages of health workers, are $+/-$ similar for both approaches of service delivery. Tables 5-7 also show the estimated number of people aged 40 years or older requiring drug treatment in these three countries. Information on the population distribution of cardiovascular risk and the level of resources available will enable policy makers to decide on the cutoff level $(\geq 20 \%$ or $\geq 30 \%$ or $\geq 40 \%$ ) at which drug treatment could be provided with public resources.

\section{Discussion}

Cardiovascular events are preventable by shifting the cardiovascular risk of populations to optimal distributions through population-wide strategies and strategies targeting high-risk groups $[2,6,32,33]$. There are two approaches to achieve this: one is a vertical single risk factor management addressing hypertension, hypercholesterolemia, and other risk factors in specific programs. The other is the approach that takes into consideration age, gender, tobacco use, diabetes, BP, and blood cholesterol in computing the total cardiovascular risk. The latter approach enables treatment decisions to be made based on the predicted 10-year cardiovascular risk.

Our results demonstrate that using a single risk factor approach to manage individual cardiovascular risk factors to prevent heart attacks and strokes would cost more than when using the total risk approach. Therefore, when available resources are limited, the total risk approach enables more accurate targeting of high-risk groups when compared with a single risk factor approach $[6,9,34]$. In the present study, most participants $(85.0 \%$ of the sample) have a low cardiovascular $(<10 \%)$. More people are at low risk $(<10 \%)$, than in developed countries [35,36]. The high percentage of the population at low risk $(<10 \%)$ highlights the potential for reduction of cardiovascular risk through population wide cost-effective public health polices [6]. For these individuals, multiple drug treatment would not be justified based on current clinical trial evidence [6].

The percentage of people at high $(\geq 30 \%$ to $<40 \%)$ or very high $(\geq 40 \%)$ risk $(0.2-2.9 \%$ in $\geq 40 \%$ vs. $0.4-4.8 \%$ in $\geq 30 \%$ ) is small. Individuals identified to have high risk $(>30 \%)$ require multiple-drug therapy to prevent fatal and nonfatal cardiovascular events [6]. All drug classes used 
Table 4. Total risk approach vs. single risk approaches (percentage of population requiring drug treatment)

\begin{tabular}{|c|c|c|c|c|c|c|c|}
\hline \multirow[b]{3}{*}{ Country and WHO subregion } & \multicolumn{4}{|c|}{ Total/risk approach } & \multicolumn{3}{|c|}{ Single risk approach } \\
\hline & \multicolumn{2}{|c|}{ CV risk $\geq 30 \%$} & \multicolumn{2}{|c|}{ CV risk $\geq 20 \%$} & \multirow[b]{2}{*}{$\begin{array}{c}B P \geq 140 / 90 \\
(S B P \geq 140+\text { isolated } \\
\text { raised } D B P), \%\end{array}$} & \multirow[b]{2}{*}{$\mathrm{TC} \geq 6.0 \mathrm{mmol} / \mathrm{L}, \%$} & \multirow[b]{2}{*}{ Total, \% } \\
\hline & $\begin{array}{c}\text { CV risk } \geq \\
30 \% \text { alone, } \%\end{array}$ & $\begin{array}{l}\text { CV risk } \geq 30 \%+ \\
\text { BP } \geq 160 / 100 \mathrm{and} / \mathrm{or} \\
\text { TC }>8.0 \mathrm{mmol} / \mathrm{L}, \%\end{array}$ & $\begin{array}{c}\text { CV risk } \geq \\
20 \% \text { alone, } \%\end{array}$ & $\begin{array}{l}\text { CV risk } \geq 20 \%+ \\
\text { BP } \geq 160 / 100 \text { and } / \text { or } \\
\text { TC }>8.0 \mathrm{mmol} / \mathrm{L}, \%\end{array}$ & & & \\
\hline Nigeria/AFR D $(1,087)$ & 2.3 & 23.3 & 5.0 & 23.3 & 48.1 & 4.8 & 52.9 \\
\hline Cuba/AMR A $(1,287)$ & 1.0 & 11.4 & 2.8 & 12.5 & 38.0 & 5.9 & 43.9 \\
\hline Iran/EMR B $(1,027)$ & 0.5 & 9.5 & 1.7 & 9.7 & 30.7 & 11.9 & 42.6 \\
\hline Pakistan/EMR D $(1,132)$ & 4.8 & 15.9 & 10.0 & 18.4 & 34.2 & 16.8 & 51.0 \\
\hline Georgia/EUR B $(1,133)$ & 3.2 & 32.7 & 9.6 & 32.1 & 58.3 & 29.9 & 88.2 \\
\hline Sri Lanka/SEAR B $(1,099)$ & 1.4 & 11.9 & 2.2 & 12.0 & 36.4 & 13.8 & 50.2 \\
\hline Nepal/SEAR D (600) & 2.6 & 12.3 & 3.9 & 12.9 & 39.7 & 7.0 & 46.7 \\
\hline China/WPR B $(1,260)$ & 0.4 & 7.0 & 1.1 & 7.0 & 28.7 & 5.3 & 34.0 \\
\hline Total $(8,625), \%(n)$ & $1.9 \%(167)$ & $15.5(1,337)$ & $4.5 \%(389)$ & $16.0(1,380)$ & $39.1(3,374)$ & $12.1(1,040)$ & $51.2 \% 4,414 / 8,625$ \\
\hline
\end{tabular}

Abbreviations: WHO, World Health Organization; CV, cardiovascular; TC, total cholesterol; BP, blood pressure; SBP, systolic blood pressure; DBP, diastolic blood pressure.

Isolated raised $\mathrm{DBP}=\mathrm{SBP}<140$ with $\mathrm{DBP}>90$.

Table 5. Comparison of medicine costs (US\$) for implementing total risk approach vs. single risk factor approach (per million population per year) in Pakistan EMER D

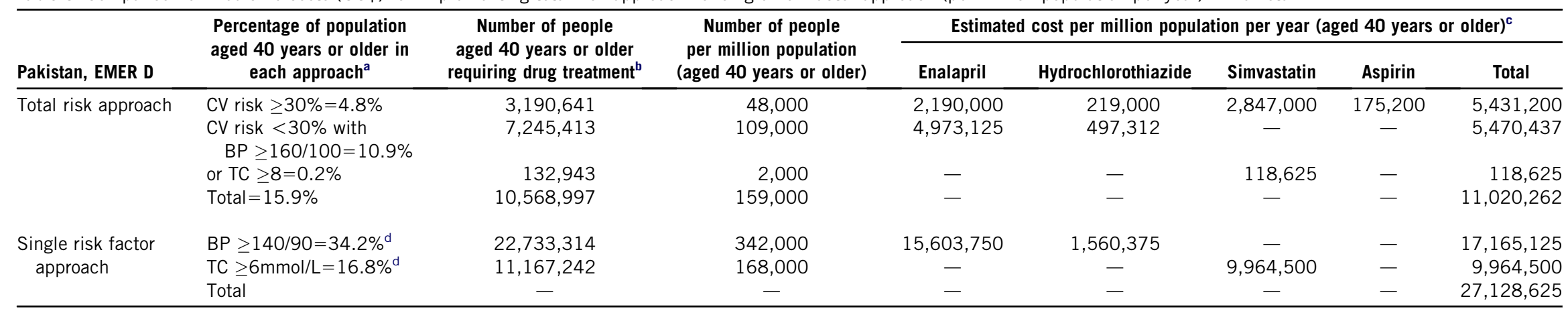

Abbreviations: CV, cardiovascular; TC, total cholesterol; BP, blood pressure; DBP, diastolic blood pressure; EMR D, WHO region for Eastern Mediterranean subregion D; SEAR D, WHO region for South-East Asia subregion D.

a Source: Table 3.

${ }^{b}$ Ministry of Population of Pakistan 2006 number of people aged 40 years or older $=66,471,681$.

c Price for 100 tablets (US\$): Enalapril $10 \mathrm{mg}$ (12.5); Hydrochlorothiazide 25 mg (1.25); Simvastatin $10 \mathrm{mg}$ (16.25); Aspirin 75 mg (1.00); one tablet per day.

d Source: Table 2, isolated DBP $\geq 100=1.9 \%$ 
Table 6. Comparison of medicine costs (US\$) for implementing total risk approach vs. single risk factor approach (per million population per year) in Nepal, SEAR D

\begin{tabular}{|c|c|c|c|c|c|c|c|c|}
\hline \multirow[b]{2}{*}{ Nepal, SEAR D } & \multirow{2}{*}{$\begin{array}{l}\text { Percentage of population } \\
\text { aged } 40 \text { years or older in } \\
\text { each approach }\end{array}$} & \multirow{2}{*}{$\begin{array}{l}\text { Number of people aged } \\
40 \text { years or older } \\
\text { requiring drug treatment }\end{array}$} & \multirow{2}{*}{$\begin{array}{l}\text { Number of people per } \\
\text { million population } \\
\text { (aged } 40 \text { years or older) }\end{array}$} & \multicolumn{5}{|c|}{ Estimated cost per million population per year (aged 40 years or older) $^{c}$} \\
\hline & & & & Enalapril & Hydrochlorothiazide & Simvastatin & Aspirin & Total \\
\hline Total risk approach & $\begin{array}{l}\mathrm{CV} \text { risk } \geq 30 \%=2.6 \% \\
\mathrm{CV} \text { risk }<30 \% \text { with } \mathrm{BP} \\
\geq 160 / 100=9.5 \%\end{array}$ & $\begin{array}{r}518,356 \\
1,893,994\end{array}$ & $\begin{array}{l}26,000 \\
95,000\end{array}$ & $\begin{array}{r}609,258 \\
2,226,135\end{array}$ & $\begin{array}{r}304,629 \\
1,113,067\end{array}$ & $\begin{array}{c}1,339,988 \\
-\end{array}$ & $\begin{array}{c}121,472 \\
-\end{array}$ & $\begin{array}{l}2,375,34 \\
3,339,20\end{array}$ \\
\hline & $\begin{array}{l}\text { or } \overline{\mathrm{T} C} \geq 8=0.2 \% \\
\text { Total }=12.3 \%\end{array}$ & $\begin{array}{r}39,874 \\
2,452,224\end{array}$ & $\begin{array}{r}2,000 \\
123,000\end{array}$ & - & - & $\begin{array}{c}103,076 \\
-\end{array}$ & - & $\begin{array}{r}103,07 \\
5,817,62\end{array}$ \\
\hline Single risk factor & $B P \geq 140 / 90=39.7 \%^{d}$ & $7,914,901$ & 397,000 & $9,302,901$ & $4,651,450$ & - & - & $13,954,35$ \\
\hline approach & $\begin{array}{l}\mathrm{TC} \geq 6 \mathrm{mmol} / \mathrm{L}=7.0 \%{ }^{\mathrm{d}} \\
\text { Total }\end{array}$ & $\begin{array}{c}1,395,574 \\
-\end{array}$ & $\begin{array}{c}70,000 \\
-\end{array}$ & - & - & $\begin{array}{c}3,607,660 \\
-\end{array}$ & - & $\begin{array}{r}3,607,66 \\
17,562,01\end{array}$ \\
\hline
\end{tabular}

Abbreviations: CV, cardiovascular; TC, total cholesterol; BP, blood pressure; DBP, diastolic blood pressure.

a Source: Table 3.

b The 2001 census number of people aged 40 years or older $=19,936,778$.

c Price for 100 tablets (US\$): Enalapril $10 \mathrm{mg}$ (6.42); Hydrochlorothiazide $25 \mathrm{mg}$ (3.21); Simvastatin $10 \mathrm{mg}$ (14.12); Aspirin $75 \mathrm{mg}$ (1.28); one tablet per day.

d Source: Table 2, isolated DBP $\geq 100=15.2 \%$.

Table 7. Comparison of medicine costs (US\$) for implementing total risk approach vs. single risk factor approach (per million population per year) in Sri Lanka, SEAR B

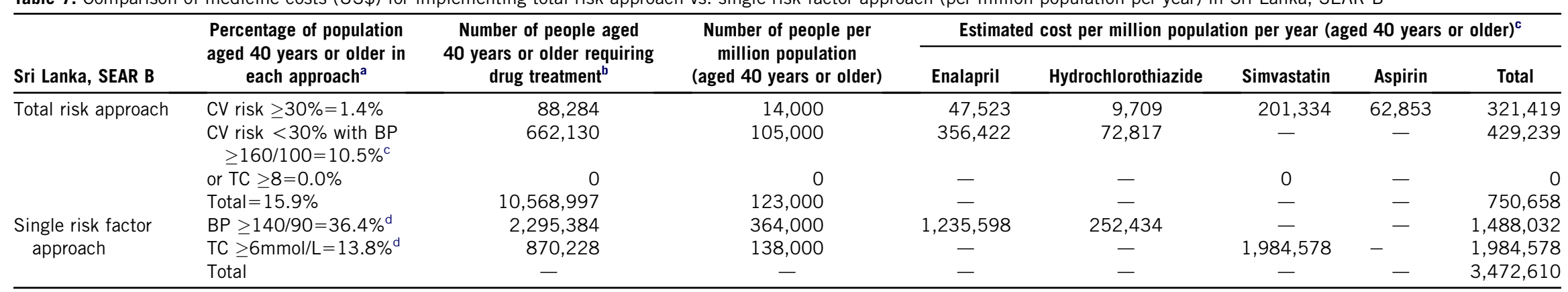

Abbreviations: CV, cardiovascular; TC, total cholesterol; BP, blood pressure; DBP, diastolic blood pressure.

a Source: Table 3.

b Latest estimate available, year 2006 number of people aged 40 years or older $=6,306,000$.

c Price for 100 tablets (US\$): Enalapril $10 \mathrm{mg}$ (0.93); Hydrochlorothiazide $25 \mathrm{mg}$ (0.19); Simvastatin $10 \mathrm{mg}$ (3.94); Aspirin $75 \mathrm{mg}$ (1.23); one tablet per day.

d Source: Table 2, isolated DBP $>100=6.6 \%$. 
for this purpose are off patent, and this approach is costeffective even in low-income countries if appropriate policies are in place to procure and distribute generic medicines $[1,24]$. Despite medicines being a major contributor to health care costs, some middle-income countries may be able to lower the threshold for drug treatment to $>20 \%$ and provide medicines in the public sector for those who qualify for treatment. We did not find that reducing the cardiovascular risk threshold for drug treatment from $30 \%$ to $20 \%$ in LMIC populations substantially increased the cost of treatment. However, as the threshold for drug treatment is lowered, there is a concomitant increase in health benefits and a modest increase in expenditure to obtain each additional unit of health benefit [10].

In most LMICs, public spending on health is inadequate, and there is excessive reliance on out-of-pocket payment as a source of health financing [37]. In these settings, prevention of heart attacks, strokes, and dialysis for kidney disease is vital to prevent costly hospital health care that result in catastrophic health expenditure for people. Therefore, it is essential that at least people with $\geq 40 \% 10$-year cardiovascular risk are given drug treatment to avoid catastrophic events. Furthermore, the drug treatment threshold need to be adjusted to suit the country context to use limited public resources equitably and target people who are at highest risk, who are likely to benefit the most.

When a single risk factor approach is used, particularly in countries with inadequate investments in health, a much greater percentage of the population at risk would be prescribed drug treatment. The consequent escalation of health care costs would be prohibitive and would contribute to the widening of already existing disparities. Furthermore, the use of the single risk factor approach may result in people at low risk being treated despite a low risk-benefit ratio. As was illustrated here, when a single risk factor approach is used, nearly $40-45 \%$ of population aged 40 years or older would require drug treatment $(39.1 \%$ antihypertensives and $12.1 \%$ lipid-lowering drugs). Adopting a total risk approach at a threshold $\geq 30 \%(1.9 \%)$ or $\geq 20 \%$ (4.5\%) would restrict the percentage of people on drug treatment to $1.9 \%$ and $4.5 \%$, respectively. If those with a persistently elevated $\mathrm{BP} \geq 160 / 100 \mathrm{~mm} \mathrm{Hg}$ and/or TC $\geq 8 \mathrm{mmol} / \mathrm{L}$ (but with 10 -year CVD risk of less than $<30 \%$ ) are added to those with a total risk $>30 \%$, as recommended in the WHO CVD prevention guideline [6], the percentage of people requiring drug treatment would increase to $15 \%$. This percentage is still much less than for the single risk factor approach.

The estimated annual cost of medicines per million population for implementing the total risk approach vs. the single risk factor approach was calculated for three selected countries with different price structure for medicines.

Several publications have reported the limited costeffectiveness of the simple risk factor approach. On the other hand, the implementation of the total cardiovascular risk is more cost-effective, the cost-effectiveness increases as the threshold is raised [1,6,10,38-41]. For example, Baker et al. [41] reports setting the threshold for treatment at a 5-year risk of disease of $20 \%$ leads to about a $10 \%$ net reduction in patients for whom drug treatment would be recommended; However, the total risk approach still averted almost 200 additional disease events over 5 years compared with single risk factors approach to treatment. These data are robust across several estimates of drug efficacy and of treatment costs [42]. Developing countries should encourage the use of inexpensive drugs that are generally available as generic formulations for prevention of CVD.

The objective of WHO recommendations [6] to base drug treatment decisions on total risk is to target limited resources on people with moderate to high cardiovascular risk for reducing premature morbidity, mortality, and disability because of cardiovascular events [43-50]. Those at high CVD risk would benefit more, in terms of number of events avoided because the relative risk reduction would be applied to a higher baseline risk [51].

The cost-effectiveness of treatment is determined by the relationship between the benefits obtained and the expenditure. The prevalence of the condition and total costs of treatment in a specific setting are directly related to the affordability. In many LMICs, interventions that are cost-effective may not be implemented, as they are not affordable. As hypertension is a highly prevalent condition for many LMIC with a health expenditure of less than 100 US\$ per capita, only a total risk factor approach may be affordable. The data presented here are important because for the first time, data on total cardiovascular risk distribution in some LMIC are made available. The economic impact of the sequelae of CVD is particularly serious in LMIC where the out-of-pocket expenditures are high. When a single risk approach is used, there is also the tendency to not treat with medicines the individuals who have a high cardiovascular risk because of mild-modest elevation of multiple risk factors (i.e., a 65 -year-old male smoker with a BP of $144 / 94 \mathrm{~mm} \mathrm{Hg}$ and TC of $5.5 \mathrm{mmol} / \mathrm{L}$ has a 10 -year cardiovascular risk $30 \%$ to $<40 \%$ but is unlikely to be treated if a single risk approach is used) [6].

The social burden of premature death, disability from CVD, and escalating costs to provide care for those suffering from CVD are development barriers and require urgent intervention by policy makers. Clearly, cardiovascular risk distribution of the population should be lowered through national health policies targeting the whole population and those at high risk. Population-wide strategies need to address tobacco use, overweight/obesity, and poor intakes of dietary fruits, vegetables, and levels of physical activity. Simultaneously, those at high risk need to be identified and targeted through health systems using cost-effective and integrated approaches [6]. Both nonpharmacologic and pharmacologic management need to be appropriately combined. All those at risk should be offered counseling and support to adopt healthy lifestyles. 
Over the last decade, total risk assessment has been adopted by a variety of national and international guidelines, supporting the above thesis that management and treatment decisions should be based on total risk rather than on single risk factor approaches $[33,34,41]$.

\section{Conclusions}

The findings of this study have important policy implications particularly for settings in which resource constraints are a major barrier for prevention of CVD. First, a total risk approach compared with a single risk factor approach reduces health care expenditure by reducing drug costs. Because the funds required for the former approach is less than that for the latter, limited resources can be more efficiently used if the total risk approach is used. Furthermore, this approach enables better targeting of those who are most likely to develop heart attacks and strokes. In addition, the high percentage of people with low-moderate cardiovascular risk demands that strategies targeting high-risk individuals be complimented with public policies that reduce the cardiovascular risk of the whole population.

\section{Acknowledgments}

We acknowledge the assistance of Dr Giorgi Pakadarze, Aieti Medical School, Tbilisi, Georgia, for his contribution during the data collection phase of this study and Miss Kristen Kai, Intern, WHO, Chronic Diseases Prevention and Management, for her contribution in data processing. In addition, we thank Dr Marikak Toidze, Sachkhere Hospital, Tbilisi, Georgia; Dr Nurys Armas and Reinaldo de la Noval, Cuban Institute of Cardiology, Havana, Cuba; Drs Ahmad Bahonar and Roya Kelishadi, Isfahan Cardiovascular Research Center, Isfahan, Iran; Drs Muhammad Shabbir and Jawad Bakhat, National Institute of Cardiology, Rawalpindi, Pakistan; Dr Emmanuel C. Ejim, Department of Medicine, University of Nigeria Teaching Hospital, Enugu, Nigeria; Dr Nalika Gunawardena, Department of Community Medicine, Faculty of Medicine, University of Colombo, Dr Navaratnasingam Janakan, Epidemiology Unit, Ministry of Health and Dr Nimalka Pannilahetti, Epidemiology Unit, Ministry of Health, Colombo, Sri Lanka; Dr Ram K.M. Shrestha, Dhulikhel Hospital Kathmandu University Teaching Hospital, Kavre, Nepal and Dr Narendra B. Rana, Kathmandu University School of Medical Science, Dhulikhel, Nepal for their contribution to data collection phase.

\section{References}

[1] The world health report 2002: reducing risks, promoting healthy life. Geneva, Switzerland: World Health Organization; 2002.
[2] Preventing chronic diseases: a vital investment. Geneva, Switzerland: World Health Organization; 2005.

[3] Summary of the 2007 European Society of Hypertension (ESH) and European Society of Cardiology (ESC) Guidelines for the Management of Arterial Hypertension. Vasc Health Risk Manag 2007;3: 783-95.

[4] Ezzati M, Lopez AD, Rodgers A, Vander Hoorn S, Murray CJL. Selected major risk factors and global and regional burden of disease. Lancet 2002;360:1347-60.

[5] Martiniuk AL, Lee CM, Lawes CM, Ueshima H, Suh I, Lam TH, et al. Hypertension: its prevalence and population-attributable fraction for mortality from cardiovascular disease in the Asia-Pacific region. J Hypertens 2007;25:73-9.

[6] World Health Organization. Prevention of cardiovascular disease: guidelines for assessment and management of total cardiovascular risk. Geneva, Switzerland: WHO; 2007.

[7] Wolf-Maier K, Cooper RS, Banegas JR, Giampaoli S, Hense H-W, Joffres M, et al. Hypertension prevalence and blood pressure levels in 6 European countries, Canada, and the United States. JAMA 2003;289:2363-9.

[8] Mathers CD, Loncar D. Projections of global mortality and burden of disease from 2002 to 2030. PLoS Med 2006;3:e442.

[9] Jamison D, Breman J, Measham A, Alleyne G, Claeson M, Evans D, et al, editors. Disease control priorities in developing countries. In: Cardiovascular disease. New York, NY: Oxford University Press; 2006:645-62.

[10] Murray CJ, Lauer JA, Hutubessy RC, Niessen L, Tomijima N, Rodgers A, et al. Effectiveness and costs of interventions to lower systolic blood pressure and cholesterol: a global and regional analysis on reduction of cardiovascular-disease risk. Lancet 2003;361: 717-25.

[11] D'Agostino RB, Russell MW, Huse DM, Ellison RC, Silbershatz H, Wilson PW, et al. Primary and subsequent coronary risk appraisal: new results from The Framingham Study. Am Heart J 2000;139: 272-81.

[12] Conroy RM, Pyörälä K, Fitzgerald AP, Sans S, Menotti A, De Backer G, et al; SCORE project group. Estimation of ten-year risk of fatal cardiovascular disease in Europe: the SCORE project. Eur Heart J 2003;24:987-1003.

[13] Jones AF, Walker J, Jewkes C, Game FL, Bartlett WA, Marshall T, et al. Comparative accuracy of cardiovascular risk prediction methods in primary care patients. Heart 2001;85:37-43.

[14] Ezzati M, Hoorn SV, Rodgers A, Lopez AD, Mathers CD, Murray CJ, Comparative Risk Assessment Collaborating Group. Estimates of global and regional potential health gains from reducing multiple major risk factors. Lancet 2003;362:271-80.

[15] Murray CJL, Lopez AD. Quantifying the burden of disease and injury attributable to ten major risk factors. In: The global burden of disease: a comprehensive assessment of mortality and disability form diseases, injuries and risk factors in 1990 and projected to 2020. Cambridge, MA: Harvard University Press; 1996:295-324.

[16] Mendis S, Lindholm LH, Mancia G, Whitworth J, Alderman M, Lim S, et al. World Health Organization (WHO) and International Society of Hypertension (ISH) risk prediction charts: assessment of cardiovascular risk for prevention and control of cardiovascular disease in low and middle-income countries. J Hypertens 2007;25: 1578-82.

[17] Woodward M, Barzi F, Martiniuk A, Fang X, Gu DF, Imai Y, et al; Asia Pacific Cohort Studies Collaboration. Cohort profile: the Asia Pacific Cohort Studies Collaboration. Int J Epidemiol 2006;35: 1412-6.

[18] Barzi F, Patel A, Gu D, Sritara P, Lam TH, Rodgers A, et al; Asia Pacific Cohort Studies Collaboration. Cardiovascular risk prediction tools for populations in Asia. J Epidemiol Community Health 2007;61:115-21.

[19] Lawes CM, Rodgers A, Bennett DA, Parag V, Suh I, Ueshima H, et al; Asia Pacific Cohort Studies Collaboration. Blood pressure 
and cardiovascular disease in the Asia Pacific region. J Hypertens 2003;21:707-16.

[20] Zhang X, Patel A, Horibe H, Wu Z, Barzi F, Rodgers A, et al; Asia Pacific Cohort Studies Collaboration. Cholesterol, coronary heart disease, and stroke in the Asia Pacific region. Int J Epidemiol 2003;32: $563-72$.

[21] Lawes CM, Parag V, Bennett DA, Suh I, Lam TH, Whitlock G, et al; Asia Pacific Cohort Studies Collaboration. Blood glucose and the risk of cardiovascular disease in the Asia Pacific region. Diabetes Care 2004;27:2836-42.

[22] Yusuf S, Hawken S, Ounpuu S, Dans T, Avezum A, Lanas F, et al; INTERHEART Study Investigators. Effect of potentially modifiable risk factors associated with myocardial infarction in 52 countries (the INTERHEART study): case-control study. Lancet 2004;364:937-52.

[23] Mackay J, Mensah GA, Mendis S, Greenlund K. The atlas of heart disease and stroke. Geneva, Switzerland: World Health Organization; 2004.

[24] Mendis S, Fukino K, Cameron A, Laing R, Filipe A Jr, Khatib O, et al. The availability and affordability of selected essential medicines for chronic diseases in six low- and middle-income countries. Bull World Health Organ 2007;85:279-88.

[25] Appel LJ, Moore TJ, Obarzanek E, Vollmer WM, Svetkey LP, Sacks FM, et al. A clinical trial of the effects of dietary patterns on blood pressure. DASH Collaborative Research Group. N Engl J Med 1997;336:1117-24.

[26] The Trials of Hypertension Prevention Collaborative Research Group. Effects of weight loss and sodium reduction intervention on blood pressure and hypertension incidence in overweight people with high-normal blood pressure. The Trials of Hypertension Prevention, phase II. Arch Intern Med 1997;157:657-67.

[27] Chobanian AV, Bakris GL, Black HR, Cushman WC, Green LA, Izzo JL Jr, et al. Seventh report of the Joint National Committee on Prevention, Detection, Evaluation, and Treatment of High Blood Pressure. Hypertension 2003;42:1206-52.

[28] South Asia Regional Procurement Unit TWB. Sri Lanka country procurement assessment report. Colombo, Sri Lanka: The World Bank; 2003.

[29] Lawes CM, Vander Hoorn S, Rodgers A. Global burden of blood-pressure-related disease, 2001. Lancet 2008;371:1513-8.

[30] Jackson R. Updated New Zealand cardiovascular risk-benefit prediction guide. BMJ 2000;320:709-10.

[31] Joint British Societies' Guidelines on the Prevention of Cardiovascular Disease in Clinical Practice: Risk Assessment Factfile 01/2006. Available at http://www.bhf.org.uk/search/results.aspx $? \mathrm{~m}=$ simple \&q $=$ guidelines + cvd + risk + assessment\&subcon $=$ BHF_main_site. Accessed March 30, 2011.

[32] Lim SS, Gaziano TA, Gakidou E, Reddy KS, Farzadfar F, Lozano R, et al. Prevention of cardiovascular disease in high-risk individuals in low-income and middle-income countries: health effects and costs. Lancet 2007;370:2054-62.

[33] Joint British recommendations on prevention of coronary heart disease in clinical practice: summary. British Cardiac Society, British Hyperlipidaemia Association, British Hypertension Society, British Diabetic Association. BMJ 2000;320:705-8.

[34] De Backer G, Ambrosioni E, Borch-Johnsen K, Brotons C, Cifkova R, Dallongeville J, et al. European guidelines on cardiovascular disease prevention in clinical practice. Third Joint Task Force of European and Other Societies on Cardiovascular Disease Prevention in Clinical Practice. Eur Heart J 2003;24:1601-10.

[35] Marma AK, Berry JD, Ning H, Persell SD, Lloyd-Jones DM. Distribution of 10-year and lifetime predicted risks for cardiovascular disease in US adults: findings from the National Health and Nutrition Examination Survey 2003 to 2006. Circ Cardiovasc Qual Outcomes 2010;3:8-14.

[36] Sacco RL, Khatri M, Rundek T, Xu Q, Gardener H, Boden-Albala B, et al. Improving global vascular risk prediction with behavioral and anthropometric factors. The multiethnic NOMAS (Northern Manhattan Cohort Study). J Am Coll Cardiol 2009;54:2303-11.

[37] Carrin G, Evans D, Xu K. Designing health financing policy towards universal coverage. Bull World Health Organ 2007;85:652.

[38] Batsis JA, Lopez-Jimenez F. Cardiovascular risk assessment-from individual risk prediction to estimation of global risk and change in risk in the population. BMC Med 2010;8:2

[39] Emberson J, Whincup P, Morris R, Walker M, Ebrahim S. Evaluating the impact of population and high-risk strategies for the primary prevention of cardiovascular disease. Eur Heart J 2004;25: 484-91.

[40] Qin X, Jackson R, Marshall R, Lee L, Cao W, Zhan S, et al. Modelling the potential impact of population-wide and targeted high-risk blood pressure-lowering strategies on cardiovascular disease in China. Eur J Cardiovasc Prev Rehabil 2009;16:96-101.

[41] Baker S, Priest P, Jackson R. Using thresholds based on risk of cardiovascular disease to target treatment for hypertension: modelling events averted and number treated. BMJ 2000;320:680-5.

[42] Gaziano TA, Opie LH, Weinstein MC. Cardiovascular disease prevention with a multidrug regimen in the developing world: a costeffectiveness analysis. Lancet 2006;368:679-86.

[43] Lewington S, Clarke R. Combined effects of systolic blood pressure and total cholesterol on cardiovascular disease risk. Circulation 2005; 112:3373-4.

[44] Asia Pacific Cohort Studies Collaboration. Joint effects of systolic blood pressure and serum cholesterol on cardiovascular disease in the Asia Pacific Region. Circulation 2005;112:3384-90.

[45] Baigent C, Keech A, Kearney PM, Blackwell L, Buck G, Pollicino C, et al; Cholesterol Treatment Trialists' (CTT) Collaborators. Efficacy and safety of cholesterol-lowering treatment: prospective meta-analysis of data from 90,056 participants in 14 randomised trials of statins. Lancet 2005;366:1267-78.

[46] Turnbull F; Blood Pressure Lowering Treatment Trialists' Collaboration. Effects of different blood-pressure-lowering regimens on major cardiovascular events: results of prospectively-designed overviews of randomised trials. Lancet 2003;362:1527-35.

[47] Sever PS, Dahlöf B, Poulter NR, Wedel H, Beevers G, Caulfield M, et al; ASCOT investigators. Prevention of coronary and stroke events with atorvastatin in hypertensive patients who have average or lower-than-average cholesterol concentrations, in the Anglo-Scandinavian Cardiac Outcomes Trial-Lipid Lowering Arm (ASCOT-LLA): a multicentre randomised controlled trial. Lancet 2003;361:1149-58.

[48] Lewington S, Clarke R, Qizilbash N, Peto R, Collins R, et al; Prospective Studies Collaboration. Age-specific relevance of usual blood pressure to vascular mortality: a meta-analysis of individual data for one million adults in 61 prospective studies. Lancet 2002;360: 1903-13.

[49] LaRosa JC, He J, Vupputuri S. Effect of statins on risk of coronary disease: a meta-analysis of randomized controlled trials. JAMA 1999;282:2340-6.

[50] Wald NJ, Law MR. A strategy to reduce cardiovascular disease by more than 80\%. BMJ 2003;326:1419. Erratum in: BMJ. 2003 Sep 13; 327 (7415): 586. BMJ. 2006 Sep; 60 (9): 823.

[51] MacMahon S, Rodgers A. The effects of blood pressure reduction in older patients: an overview of five randomized controlled trials in elderly hypertensives. Clin Exp Hypertens 1993;15:967-78. 